\title{
Unplanned Reoperation After Percutaneous Endoscopic Discectomy For Lumbar Disc Herniation:A Clinical Report From China
}

Hai-ting Wu ( $\square$ wht1551@163.com )

University of Chinese Academy of Science https://orcid.org/0000-0001-5725-021X

Qingjiang Pang

University of Chinese Academy of Sciences

Yun Wang

University of Chinese Academy of Sciences

\section{Research Article}

Keywords: Percutaneous spinal endoscopic, lumbar, discectomy, reoperation

Posted Date: January 31st, 2022

DOl: https://doi.org/10.21203/rs.3.rs-1205912/v1

License: (c) (i) This work is licensed under a Creative Commons Attribution 4.0 International License.

Read Full License 


\title{
Unplanned reoperation after percutaneous endoscopic discectomy for lumbar disc herniation:a clinical report from China
}

\author{
Hai-ting Wu ${ }^{1}$, Qingjiang Pang ${ }^{2}$, Yun Wang ${ }^{1 *}$ \\ Departments of ${ }^{1}$ Spinal Surgery, ${ }^{2}$ Orthopaedics, Hwa Mei Hospital, University of Chinese Academy \\ of Sciences. Ningbo No.2 Hospital. Ningbo Institute of Life and Health Industry, University of \\ Chinese Academy of Sciences \\ Acknowledgements: This study was supported by the Ningbo natural science foundation (No. \\ 2018A610265).
}

\begin{abstract}
Objective: To investigate the causes of unplanned reoperation after percutaneous endoscopic discectomy for lumbar disc herniation.

Methods: 853 patients with lumbar disc herniation were treated by percutaneous endoscopic discectomy in Hwa Mei hospital from January 2018 to June 2021, of which 18 patients received unplanned reoperation. There were 7 males and 11 females, aged from 38 to 72 , with an average of $(56.8 \pm 11.3)$ years. There were 1 case of segment L3/4, 11 cases of segment L4/5, and 1 case of segment L3/4+L4/5. The follow-up time after reoperation ranged from 1 to 35 months, with an average of 8.5 months. VAS score, ODI index and MacNab criteria were adopted to evaluate the curative effect of the initial and revision operation. We made a descriptive analysis of the clinical data of patients with unplanned reoperation, so as to summarize the poor curative effect after percutaneous endoscopic surgery and the reasons for reoperation.
\end{abstract}

Results: A total of 18 patients with unplanned reoperation were collected, of which 2 patients received twice unplanned reoperation. All the 18 cases had ipsilateral herniation, including ipsilateral herniation in 17 cases and contralateral protrusion in 1 case. The methods of reoperation: 13 cases of PELD, 4 cases of decompression and internal fixation $(\mathrm{PLIF} \times 1, \mathrm{TLIF} \times 3), 1$ case of MED, 1 case of Endo-LIF, and 1 case of debridement. The causes of reoperation included incomplete decompression (residual nucleus pulposus, residual endplate, residual bone), recurrence, postoperative infection, nerve injury, hematoma, pseudocyst and so on. The follow-up time after reoperation ranged from 1 to 22 months, with an average of $8.61 \pm 3.52$ months. The VAS score of low back pain decreased from $3.27 \pm 1.24$ before operation to $1.21 \pm 0.32$ at the last follow-up, the VAS score of leg pain decreased from $5.12 \pm 2.15$ before operation to 1.98 \pm 1.20 at the last follow-up. The ODI index decreased from $32 \pm 16 \%$ to $10.4 \pm 6$, and the difference was statistically significant $(\mathrm{P}<0.05)$. At the last follow-up, the clinical efficacy was evaluated according to MacNab criteria (18 cases), including excellent in 14 cases, good in 3 cases, fair in 1 case and poor in 0 cases. The excellent and good rate was $94.4 \%$.

Conclusion: There is the possibility of unplanned reoperation in the removal of nucleus pulposus under PELD. Besides, the appropriate operation method should be chosen according to the specific conditions of the lesion before operation. Incomplete decompression is the main cause of unplanned reoperation after PELD. Other causes include recurrence, infection, hematoma, nerve injury, pseudocyst. 


\section{Key words: percutaneous spinal endoscopic, lumbar, discectomy, reoperation}

Lumbar disc herniation (LDH) is a common disease in clinic, which often causes discomfort such as low back pain, lower limb sciatica and numbness. Severe patients need surgical treatment. With the development of spinal minimally invasive technology, percutaneous endoscopic lumbar discectomy (PELD) has achieved good clinical results, and has been gradually recognized by spinal surgeons and patients. However, there is still a lack of high-quality literature reports on postoperative complications and long-term follow-up of PELD, especially the lack of systematic analysis of patients with poor postoperative efficacy and unplanned reoperation. According to the statistics of some scholars, the reoperation rate of PELD can be as high as $10 \%(7.92-12.40 \%)^{[1]}$.

At present, doctors' selection of the way for operation is heterogeneous in view of the lack of "expert consensus" on the causes and options of reoperation after PELD. The factors, mechanism and clinical features of reoperation may be complex and need to be summarized. This clinical data of patients who underwent unplanned reoperation in our hospital in the past 3 years were collected and reported as follows.

\section{Materials and methods}

From January 2018 to June 2021, a total of 853 patients of LDH were treated with PELD in Hwa Mei Hospital, University of Chinese Academy of Sciences, including 18 patients who received unplanned reoperation. There were 7 males and 11 females, whom aged from 38 to 72 , with an average of $(56.8 \pm 11.3)$ years. There were 1 case of segment L3/4, 11 cases of segment L4/5, and 1 case of segment L3/4+L4/5. The follow-up time after reoperation ranged from 1 to 35 months, with an average of 8.5 months. There were 3 patients with poor reoperation after PELD from other hospital, and 2 patients received twice unplanned reoperations in 18 patients. The total unplanned reoperation rate was $2.1 \%$.

All cases were approved by the patient or family, and reported to the hospital ethics committee for review and approval.

Inclusion criteria: 1 . The clinical effect after PELD was not good, and received unplanned reoperation, 2. The revision operation was performed in our hospital.

Exclusion criteria: 1. Patients with incomplete clinical data and follow-up data. 2. Patients complicated with serious basic diseases such as cardiopulmonary and cerebrovascular diseases, which affected the evaluation of clinical efficacy. 3. Patients were scheduled to undergo two or more operations. 4. Patients who performed invasive procedures such as CT-guided puncture and sacral canal injection.

The indications for the first treatment of LDH with PELD in our hospital were as follows: 1. Patients who had low back pain with lower limb radiation pain and / or numbness, 2. CT or MRI showed lumbar disc herniation clearly, and consistent with symptoms and signs, 3 . Regular conservative treatment was ineffective for more than 3 months, or symptoms seriously affected daily work and life. 4. Patients who had lumbar fracture, infection, tumor, history of lumbar surgery and so on were excluded.

Criteria for poor postoperative effect ${ }^{[2-3]}$ :(1) VAS score of postoperative low back / leg pain $\geq 4$; (2)Postoperative CT/MRI examination showed ipsilateral or contralateral disc herniation (not the original herniation), compressed nerve root; (3)Postoperative symptom relieved, but aggravated again after discharge; (4)Patients who residual nucleus 
pulposus tissue or displacement of original herniated nucleus pulposus was confirmed by reoperation.

A retrospective clinical study was adopted to collect the data of patients pre-operation, post-operation, unplanned reoperation and follow-up time, including clinical manifestation, ODI index, VAS score of low back / leg pain, X/CT/MRI,etc. Statistics contents include the initial and second surgical options, operation time, intra-operative findings, postoperative follow-up results, etc. Clinical data collection was mainly through consulting the hospital electronic medical record system and imaging system. By contacting the patient's own outpatient appointment reexamination and telephone, research assistants can obtain the follow-up data. According to the MacNab standard, we evaluated the curative effect and analyzed the causes for reoperation.

\section{Results}

A total of 18 reoperative patients were collected, of which 2 patients underwent twice unplanned reoperation(total operation $\times 20$ ). The methods of reoperation were different, including 13 cases of PELD, 1 case of PLIF, 3 cases of TLIF, 1 case of MED, 1 case of Endo-LIF and 1 case of debridement (Table 1).

The causes of reoperation included incomplete decompression (10 cases / 11 operations, 55\%) and recurrence (4 cases, 20\%). ), nerve injury ( 1 case, $5.0 \%$ ), postoperative infection ( 1 case, $5.0 \%$ ), hematoma ( 2 cases, $10.0 \%$ ), symptomatic pseudocyst of disc (1 case, 5.0\%), etc. Typical cases are shown in Fig. 1-4.

All the 18 patients underwent the revision operation successfully. Besides, there was no important vascular and nerve injury during discectomy. The follow-up time after reoperation ranged from 1 to 22 months, with an average of $8.61 \pm 3.52$ months. The VAS score of low back pain decreased from $3.27 \pm 1.24$ before operation to $1.21 \pm 0.32$ at the last follow-up, the VAS score of leg pain decreased from $5.12 \pm 2.15$ before operation to $1.98 \pm 1.20$ at the last follow-up, and the ODI index decreased from $32 \pm 16 \%$ to $10.4 \pm 6 \%$. The difference was statistically significant $(\mathrm{P}<0.05)$. Case 1 had a long-term follow up recurrence, and Case 14 had no obvious improvement in short-term symptoms after operation, reexamination revealed incompletion of the disc decompression. These 2 cases underwent the second unplanned reoperation. At the last follow-up, the clinical efficacy was evaluated according to MacNab criteria (18 cases), including excellent in 14 cases, good in 3 cases, fair in 1 case and poor in 0 cases. Excellent and good rate was $94.4 \%$.

\section{Discussion}

\section{Cause analysis}

\subsection{Incomplete decompression}

At present, incomplete decompression is the main reason to reoperate without plan . It mainly includes nucleus pulposus residue, endplate residue, bone mass residue, etc. The residual nucleus pulposus refers to that only part of the nucleus pulposus protruding into the spinal canal is removed at the initial operation, and the residual nucleus pulposus still oppresses the nerve root, or the residual nucleus pulposus in the intervertebral is not removed during the operation. It often occurs in migrating disc herniation or central giant disc herniation. The criteria for determining the residual nucleus pulposus were as follows: (1)the size of the nucleus pulposus removed during the operation was different from that assessed before operation; (2)the pulsation of the dural sac and / or nerve root 
was not significantly restored during the operation; (3)the lateral recess was not explored or enlarged; (4)confirmed by post-operative MRI ; (5)confirmed by reoperation. The residue of nucleus pulposus in lateral recess was more common in beginners' PELD operation. Burton ${ }^{[4]}$ reported that $56 \%-71 \%$ of patients with reoperation for $\mathrm{LDH}$ had lateral recess stenosis. After discectomy, the loss of intervertebral space height, relaxation of ligaments and increased stress of facet joints accelerated its degeneration and proliferation, resulting in secondary lateral recess stenosis. In case 4, 6, 14 and 16, the decompression was insufficient, the residual nucleus pulposus was confirmed during the second decompression, and the postoperative symptoms were significantly improved. Case 2 diagnosed cauda equina syndrome before operation, removed a large mass of nucleus pulposus during posterior poroscope decompression, but still left part of symptoms after operation. MRI showed that there were still residual signs of nucleus pulposus, and the residual nucleus pulposus was confirmed during TLIF operation.Finally, the symptoms were basically improved 4 months after operation.

The residual endplate often occurred in the severe degeneration of intervertebral disc. The cartilage endplate fell off after the operation, and entered into the spinal canal through the fibrous annulus, oppressing the dura mater and nerve root though the herniated nucleus pulposus and intervertebral space degenerative nucleus pulposus had been removed during the operation. In case 3, the symptoms worsened after the operation, and MRI showed that there was space occupying in the vertebral canal. During the second exploration, it was found that part of the cartilage of the superior endplate of the sacral vertebra was displaced, protruded from the fibrous annulus, and compressed the nerve root and dural sac. In case 10, PTED was performed under local anesthesia, the pain of the affected limb was not improved after operation, and aggravated after exercise. Postoperative CT/MRI showed that the intervertebral foramen bone remained in the spinal canal and compressed the nerve root. MED exploration was performed again under general anesthesia and was taken out again during the operation. The curative effect of $\mathrm{MacNab}$ in the last follow-up was good. The reason for the analysis was that the intervertebral foramen could not be formed at one time under local anesthesia. In addition, the bone mass entered the spinal canal during the molding, but could not be found in time during the operation.

Incomplete decompression often occurs in early surgical cases, the reasons included poor surgical technique, inadequate intraoperative exploration, local anesthesia patients can not tolerate long-term operation,etc. Complete decompression of the responsible site must be achieved during PELD, especially the patients with lateral recess stenosis are easy to leave protruding and compression.

\subsection{Recurrence}

Scholars believe that recurrent lumbar disc herniation (RLDH) refers to the remission of symptoms after discectomy for at least 6 months. The residual intervertebral disc tissue of the same segment in the operative side or contralateral side causes neurological symptoms ${ }^{[5]}$.

The cause of "recurrence" may be the existence of annulus fibrosus rupture before operation or iatrogenic injury of fibrous annulus during operation, the annulus fibrosus failed to heal in a short time after operation, and the degenerative nucleus pulposus protruded again in a "painless period" after operation. According to literature statistics, the recurrence rate is about $3.92 \%{ }^{[6-7]}$. Cases $1,7,8$ and 9 were recurrent cases after 
operation, and the recurrence rate was about $0.47 \%$ (4/853), which was lower than that in the literature. The authors analyzed that the main reason might be that the follow-up period of this study was short (8.61 \pm 3.52 months), and the recurrence rate might further increase with the extension of follow-up time. Moreover, some patients did not received revision surgery in our hospital and other reasons may also affect the recurrence rate statistics.

There are two different views on whether it is necessary to completely remove the nucleus pulposus of the intervertebral disc. On one hand, the biomechanical changes of lumbar vertebrae should be reduced as much as possible, using the limited resection method of removing only the protuberant fibrous annulus and scraping off part of the degenerative nucleus pulposus below it ${ }^{[8]}$; On the other hand, nucleus pulposus tissue should be removed as much as possible. The more tissue left over is, the higher the recurrence rate is ${ }^{[9-10]}$. At present, most scholars advocate the latter point of view ${ }^{[10]}$. Carrage et al ${ }^{[11]}$ believed that the integrity of the annulus fibrosus of the herniated disc was significantly related to postoperative recurrence. According to the intraoperative findings, the herniation of the intervertebral disc was divided into four types: type I (49\%, fragment-fissure) nucleus pulposus was free, and the annulus fibrosus was less damaged. Type II (18\%, fragment-defect type) has larger protrusions, obvious nerve root compression, large annulus fibrosus defect $(>6 \mathrm{~mm})$, and nucleus pulposus can be easily removed. Type III (23\%, fragment-inclusion) annulus was not damaged, but there were free fragments of nucleus pulposus under the annulus after incision. Type IV (9\%, nonfragment-inclusion) fibrous annulus is relatively complete, and there are no free nucleus pulposus fragments after incision, so it is difficult to remove. The recurrence rate of type I and type III was low, while that of type II and type IV was high. Besides, excessive resection of bony structure in the first operation leads to segmental instability after operation, which accelerates intervertebral disc degeneration and is easy to cause recurrence. Some scholars believe that there is no significant relationship between sex, age and postoperative recurrence ${ }^{[12]}$. However, it is generally believed that young men are more likely to relapse. It is not easy to remove during operation because the intervertebral disc degeneration of young patients is mild, and the toughness of disc is large; young male patients have a large amount of activity and a high probability of injury, so they are easy to protrude again ${ }^{[13]}$.

\subsection{Nerve injury}

There have been more than 2000 cases of PELD surgery since endoscopic surgery was carried out in our hospital at the end of 2014. However, iatrogenic nerve injury is rare. The injury of epistatic nerve root caused by "extrusion" of instruments and sleeve of PTED is common. Besides, the iatrogenic injury of "target"(inferiority ) nerve root under endoscopy is rare in the study. At present, iatrogenic injuries caused by endoscopy in our hospital are mainly treated conservatively. In addition, part of the follow-up cases recover well in the middle and long stage.

During the study cycle,only one patient (case 15) was collected. The patient underwent L4/5 PELD under local anesthesia, and the dural sac injury occurred introoperation. The size of the tear was about $2 \times 2 \mathrm{~mm}$ and was not repaired. There was no iatrogenic epistatic or inferiority nerve root injury during the operation, and the drainage tube was indwelled. The symptoms of the patient were relieved immediately. However, the symptoms of lower limb fatigue and grade 1 of extensor dorsi muscle strength 
appeared after pulling out the drainage tube on the second day after operation. MRI showed effusion in the operation area, and no obvious residual sign of nucleus pulposus was found. After one day of symptomatic treatment, there was no improvement, so poroscope exploration was performed again under local anesthesia. During the process, it was found that a small amount of cauda equina nerve herniated from the dural sac and entrapment, and could not be reclaimed by itself. No residual nucleus pulposus and hematoma were found. The laceration of the dural sac was dilated properly and the incision was tightly sutured after receiving the cauda equina nerve. The symptoms of the patient improved gradually after operation. The authors called this phenomenon "cauda equina dural herniation", which is rarely reported in endoscopic surgery. In the past, it was common in lumbar burst fracture, and some cauda equina root filaments were found to extrude from the dural sac tear to form a herniation, which was called lumbar burst fracture with "traumatic cauda equina dural herniation". Cammisa et al [14] reported that $18 \%$ of 60 patients with spinal burst fracture were complicated with dural sac laceration, and all patients with dural sac laceration had neurological dysfunction. Keenen et al ${ }^{[15]}$ reported that $7.7 \%$ of patients undergoing thoracolumbar surgery had dorsal dural sac tears. In addition, Carl et al ${ }^{[16]}$ reported ventral dural sac tears in $10 \%$ of patients.

The incidence of reoperation due to cauda equina dural herniation was $5.6 \%$, and the total incidence $<0.12 \%$. The incidence of dural sac herniation during endoscopy was very low. It was considered that some patients with cauda equina dural herniation might not have severe symptoms and the compressed cauda equina nerve replaces itself. Besides, the predictive effect of MRI on the occurrence of cauda equina dural hernia was unknown.

\subsection{Postoperative infection}

The overall probability of surgical site infection (SSI) was low, and there were occasional clinical reports of intervertebral space infection due to the small incision and continuous irrigation with sterile saline during the operation. The main causes were intraoperative contamination and hematogenous infection. One patient with postoperative infection revision was collected, and the anti-infective treatment was not improved, and finally recovered after open debridement operation. Because the trauma is relatively small and there is no internal fixation implantation, the postoperative infection is relatively easy to deal with. However, postoperative infection can be complicated with a variety of complications, which can be life-threatening. As a consequence, patients' condition should be strictly evaluated before and after operation, active prevention, antiinfection treatment and strict asepsis during operation.

\subsection{Hematoma}

Asymptomatic epidural hematoma is very common in lumbar surgery. In addition, it can be found by MRI that $89 \%$ of patients without drainage after lumbar surgery will develop asymptomatic epidural hematoma ${ }^{[17]}$. However, if it occurs and fails to be detected and treated in time, it may lead to serious complications. According to incomplete statistics, the probability of postoperative symptomatic epidural hematoma is about $0.10 \% \sim 0.24 \%$ in all spinal operations ${ }^{[18]}$.

Generally speaking, epidural hematoma occurs within 24 hours after operation. However, some scholars have reported that the occurrence of lumbar hematoma can be delayed until after the drainage tube is removed, or even 3 days after operation. Almost all patients with epidural hematoma have evidence of nerve damage. Kao et al ${ }^{[19]}$ 
reported that about $80 \%$ of patients with lumbar epidural hematoma had progressive muscle strength decline, $76 \%$ had Sellar numbness, and $56 \%$ had sudden severe pain. When any symptom occurs, the patient needs to undergo an MRI test to evaluate the occurrence of an epidural hematoma. Once symptoms appear and are confirmed by MRI, the patient needs to undergo an emergency reoperation to remove the hematoma. Kao et $\mathrm{al}^{[19]}$ believed that there was a significant correlation between the clearance time of hematoma and the recovery of postoperative neurological function. In patients with complete recovery of neurological function, the average clearance time of hematoma was 7.4h. However, the average clearance time of patients with neurological dysfunction was $17.9 \mathrm{~h}$.

Two cases of postoperative hematoma were included (case 11 17). All of them were found on the second day and underwent emergency poroscope exploration and hematoma clearance $(>18 \mathrm{~h})$. The muscle strength of lower extremities recovered after operation, but mild neurological dysfunction was left.

\subsection{Symptomatic discal pseudocyst}

In 2009, Young et al ${ }^{[20]}$ proposed for the first time a rare complication after endoscopic surgery: postoperative discal pseudocyst (PDP), which is defined as an epidural cystic lesion in the spinal canal, and the cystic cavity is connected with the corresponding surgical segment of the intervertebral disc. The difference between PDP and ordinary intervertebral disc cysts is that the wall of the cyst is incomplete and the cystic cavity can communicate with the disc.

There have been more than 2000 cases of lumbar PELD surgery in our department since 2014. There were 5 cases of postoperative symptomatic pseudocyst, 4 cases were improved after conservative treatment, and 1 case (case 5) underwent reoperation. At present, there is a lack of unified understanding of the etiology, pathogenesis and treatment of PDP in academic circles. Previous Kang et al ${ }^{[21]}$ reported that the incidence of PDP in a single center with large samples was about $1 \%(15 / 1503)$, which usually occurred one month after operation. It was mostly in patients with mild intervertebral disc degeneration and was common in men. Japanese scholar Shiboi ${ }^{[22]}$ reported that the incidence was relatively low. From 2009 to 2016 , only one of the 359 patients developed PDP, with an incidence of $0.28 \%$. According to our clinical experience, asymptomatic pseudocyst of intervertebral disc was occasionally found during postoperative MRI follow-up, but PDP with low back pain was relatively rare. Combined with previous literature reports ${ }^{[21-23]}$, most of the cysts can be absorbed after conservative treatment for PDP patients with no progressive neurological impairment.

\section{Limitations and attentions}

1. Parts of re-operative patients were not performed in our hospital and lost the opportunity of follow-up. In addition, some patients with poor postoperative effect did not reoperate, which is related to many factors, such as pain tolerance, unwillingness to fusion surgery,etc. 2 . This study was a single-center retrospective study with a short follow-up time. In the follow-up, a multicenter study will be conducted. With the extension of follow-up time, the number of reoperation cases may increase, which is conducive to cause analysis. 3 . The clinical experience of the primary surgery surgeon and the grasp of the indications may have an impact on the incidence of reoperation. Some of the reasons, such as incomplete removal of nucleus pulposus, may gradually 
decrease with the accumulation of experience of the surgical team. As a consequence, the reasons for reoperation may not be exactly the same in different research cycles. 4 . In the long-term follow-up after PELD, some patients had complications such as intervertebral space collapse and segmental instability. However, the patients refused fusion revision because of many reasons (such as strong pain tolerance, economic reasons, fear of internal fixation, etc.). The postoperative curative effect of some cases was poor and improved after invasive treatment, which is not in the scope of this study.

In a word, there is the possibility of unplanned reoperation in discectomy under PELD. The appropriate operative approaches should be chosen according to the specific conditions of the lesion before operation. Incomplete decompression is the main cause of unplanned reoperation after PELD. Other causes include recurrence, infection, hematoma, nerve injury and symptomatic intervertebral disc pseudocyst. 
Table 1. Summary of unplanned reoperative patients after percutaneous endoscopic discectomy

\begin{tabular}{|c|c|c|c|c|c|c|c|c|c|}
\hline Case & Sex & Age & $\begin{array}{l}\text { Operative } \\
\text { segment }\end{array}$ & $\begin{array}{l}\text { Primary } \\
\text { surgical } \\
\text { hospital }\end{array}$ & $\begin{array}{l}\text { Primary } \\
\text { surgical } \\
\text { option }\end{array}$ & $\begin{array}{l}\text { Causes of } \\
\text { reoperation }\end{array}$ & $\begin{array}{l}\text { Interval } \\
\text { time } \\
\text { between } \\
\text { surgerys } \\
\end{array}$ & $\begin{array}{l}\text { Reoperative } \\
\text { option }\end{array}$ & $\begin{array}{l}\text { Prognosis } \\
\text { (MacNab } \\
\text { criterion) }\end{array}$ \\
\hline \multirow[t]{2}{*}{1} & $\mathrm{~F}$ & 49 & $\mathrm{~L} 5 / \mathrm{S} 1$ & $\begin{array}{l}\text { Other } \\
\text { hospital }\end{array}$ & PEID & Recurrence & 3 years & PEID & \\
\hline & & & & & & $\begin{array}{l}\text { Incomplete } \\
\text { decompression }\end{array}$ & 2 months & PTED & Excellent \\
\hline 2 & M & 40 & $\mathrm{~L} 5 / \mathrm{S} 1$ & $\begin{array}{l}\text { Hwa Mei } \\
\text { hospital } \\
\text { (Fig. 1) }\end{array}$ & PEID & $\begin{array}{l}\text { Nucleus pulposus } \\
\text { residue、Cauda equina } \\
\text { syndrome symptoms not } \\
\text { improved }\end{array}$ & 1 week & PLIF & Good \\
\hline 3 & $\mathrm{~F}$ & 51 & $\mathrm{~L} 5 / \mathrm{S} 1$ & $\begin{array}{l}\text { Hwa Mei } \\
\text { hospital }\end{array}$ & PEID & $\begin{array}{l}\text { Incomplete } \\
\text { decompression, } \\
\text { cartilage endplate displace } \\
\text { and depress nerve }\end{array}$ & 8 days & PTED & Excellent \\
\hline 4 & M & 28 & $\mathrm{~L} 4 / 5$ & $\begin{array}{l}\text { Other } \\
\text { hospital }\end{array}$ & PTED & $\begin{array}{l}\text { Incomplete } \\
\text { decompression }\end{array}$ & 2 months & PTED & Excellent \\
\hline 5 & $\mathrm{~F}$ & 60 & $\mathrm{~L} 4 / 5$ & $\begin{array}{l}\text { Hwa Mei } \\
\text { hospital } \\
\text { (Fig. 2) }\end{array}$ & PTED & PDP & 40 days & PTED & Excellent \\
\hline 6 & M & 58 & $\mathrm{~L} 4 / 5$ & $\begin{array}{l}\text { Hwa Mei } \\
\text { hospital }\end{array}$ & PEID & Nucleus pulposus residue & 3 days & PEID & Excellent \\
\hline 7 & $\mathrm{~F}$ & 58 & $\mathrm{~L} 5 / \mathrm{S} 1$ & $\begin{array}{l}\text { Hwa Mei } \\
\text { hospital }\end{array}$ & PEID & Recurrence & 8 months & TLIF & Excellent \\
\hline 8 & $\mathrm{~F}$ & 66 & $\mathrm{~L} 4 / 5$ & $\begin{array}{l}\text { Other } \\
\text { hospital }\end{array}$ & PTED & Recurrence & 1 year & TLIF & Excellent \\
\hline 9 & $\mathrm{~F}$ & 65 & $\mathrm{~L} 4 / 5$ & $\begin{array}{l}\text { Hwa Mei } \\
\text { hospital }\end{array}$ & PEID & Recurrence & 6 months & Endo-LIF & Excellent \\
\hline 10 & M & 45 & $\mathrm{~L} 4 / 5$ & $\begin{array}{l}\text { Hwa Mei } \\
\text { hospital }\end{array}$ & PTED & $\begin{array}{l}\text { Bone pieces } \\
\text { residue(foramen } \\
\text { intervertebrale molding } \\
\text { bone) }\end{array}$ & 3 days & MED & Excellent \\
\hline 11 & $\mathrm{~F}$ & 32 & $\mathrm{~L} 4 / 5$ & $\begin{array}{l}\text { Hwa Mei } \\
\text { hospital } \\
\text { (Fig. 3) }\end{array}$ & PEID & Hematoma & 2 days & PEID & Good \\
\hline 12 & $\mathrm{M}$ & 52 & $\mathrm{~L} 5 / \mathrm{S} 1$ & $\begin{array}{l}\text { Own } \\
\text { (Fig. 4) }\end{array}$ & PEID & Infection & 1 month & $\begin{array}{l}\text { MED } \\
\text { exploration } \\
\text { and opened } \\
\text { debridement }\end{array}$ & Excellent \\
\hline 13 & $\mathrm{~F}$ & 50 & $\mathrm{~L} 4 / 5$ & $\begin{array}{l}\text { Hwa Mei } \\
\text { hospital }\end{array}$ & PEID & $\begin{array}{l}\text { Disc calcification displace } \\
\text { and contralateral spinal } \\
\text { stenosis }\end{array}$ & 3 days & $\begin{array}{l}\text { Contralateral } \\
\text { PEID }\end{array}$ & Excellent \\
\hline \multirow[t]{2}{*}{14} & M & 66 & $\mathrm{~L} 3 / 4 、 \mathrm{~L} 4 / 5$ & $\begin{array}{l}\text { Hwa Mei } \\
\text { hospital }\end{array}$ & PTED & $\begin{array}{l}\text { Incomplete } \\
\text { decompression 、free disc } \\
\text { fragments residual(L3/4) }\end{array}$ & 6 days & $\begin{array}{l}\operatorname{PEID}(2 \\
\text { segments })\end{array}$ & \\
\hline & & & & & & $\begin{array}{l}\text { Incomplete } \\
\text { decompression of } \\
\text { the anterior edge of dural } \\
\text { sac, nucleus pulposus } \\
\text { residue }\end{array}$ & 13 days & PTED(L3/4) & Good \\
\hline
\end{tabular}




\begin{tabular}{|c|c|c|c|c|c|c|c|c|c|}
\hline 15 & $\mathrm{~F}$ & 79 & $\mathrm{~L} 4 / 5$ & $\begin{array}{l}\text { Hwa Mei } \\
\text { hospital }\end{array}$ & PTED & $\begin{array}{l}\text { Nerve injury (cauda } \\
\text { equina dural herniation) }\end{array}$ & 3 days & PTED & Fair \\
\hline 16 & M & 71 & $\mathrm{~L} 4 / 5$ & $\begin{array}{l}\text { Hwa Mei } \\
\text { hospital }\end{array}$ & PEID & Nucleus pulposus residue & 3 days & TLIF & Excellent \\
\hline 17 & $\mathrm{~F}$ & 46 & $\mathrm{~L} 3 / 4$ & $\begin{array}{l}\text { Hwa Mei } \\
\text { hospital }\end{array}$ & PTED & Hematoma & 2 days & PTED & Excellent \\
\hline 18 & $\mathrm{~F}$ & 59 & $\mathrm{~L} 4 / 5$ & $\begin{array}{l}\text { Hwa Mei } \\
\text { hospital }\end{array}$ & PTED & $\begin{array}{l}\text { Incomplete } \\
\text { decompression }\end{array}$ & 2 months & PTED & Excellent \\
\hline
\end{tabular}

Note:PTED: percutaneous transforaminal endoscopic discectomy, PEID: pereutaneous endoscopic interlaminar discectomy. PDP: postoperative discal pseudocyst. EndoLIF: endoscopic lumbar interbody fusion. 

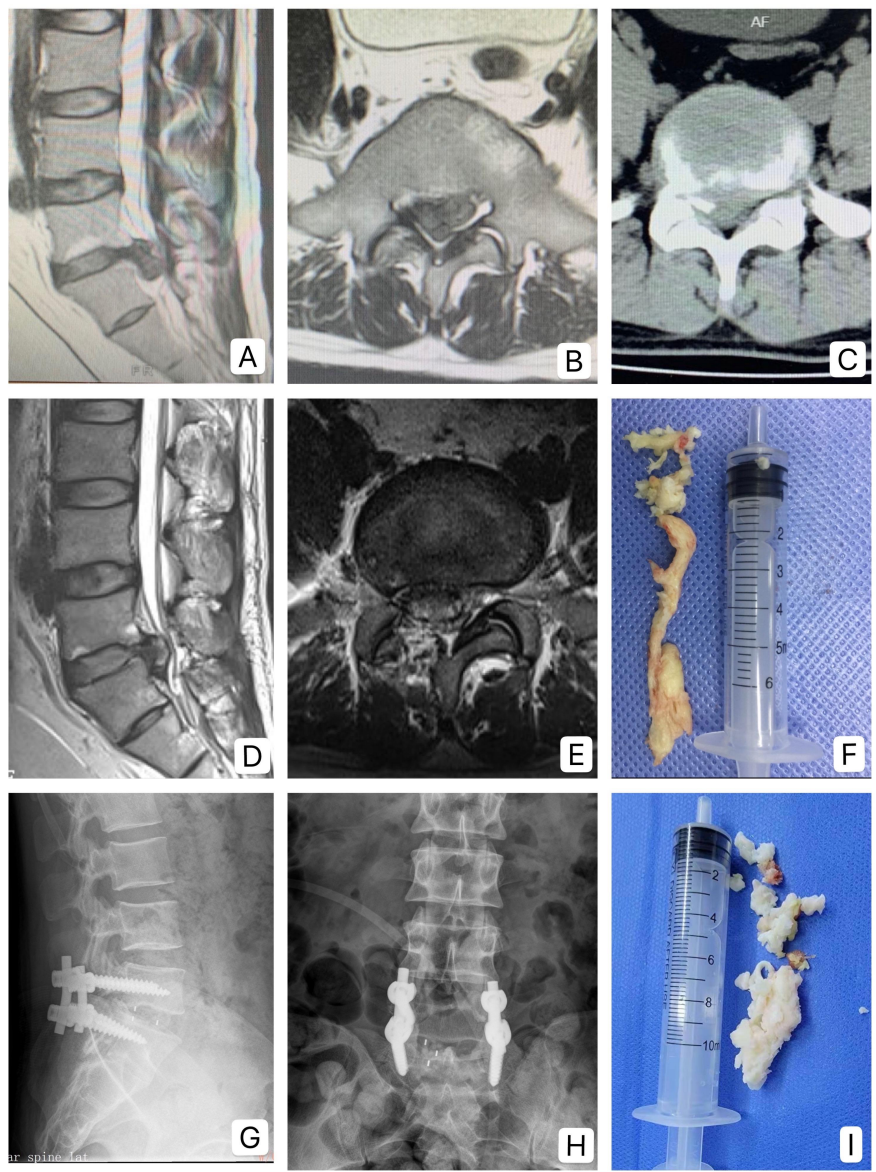

Fig. 1. Case 2 was a male aged 39yrs. Complaint: Recurrent low back and leg pain for 10 years, sudden aggravation with defecation and defecation disorders for 2 days. Diagnosis: cauda equina syndrome, lumbar disc herniation (L5/S1, prolapse). A. B: preoperative MRI showed giant prolapse of L5 / S1 intervertebral disc, partial prolapse, partial calcification (C) and secondary spinal canal stenosis. PELD operation was performed after general anesthesia for the first time. During the operation, the dural sac and nerve root ventral, lateral and dorsal $270^{\circ}$ decompression were explored. Postoperative routine MRI revealed partial residual nucleus pulposus (D, E), and nucleus pulposus tissue (F) was removed during operation. The numbness of lower extremities and Sellar region was significantly improved, but the function of stool was still dysfunction. the straight leg elevation test of right lower extremities was improved $\left(50^{\circ}\right)$, and the metatarsal flexor strength of right toes was the same (IV grade). Unplanned PLIF operation (G, H) was performed again after operation, and a large piece of protruded nucleus pulposus (I) was confirmed during the operation, which was located at the level of intervertebral space, dural sac and ventral nerve root. During the follow-up for more than 4 months, the original symptoms were basically relieved and mild dysuria was left. 

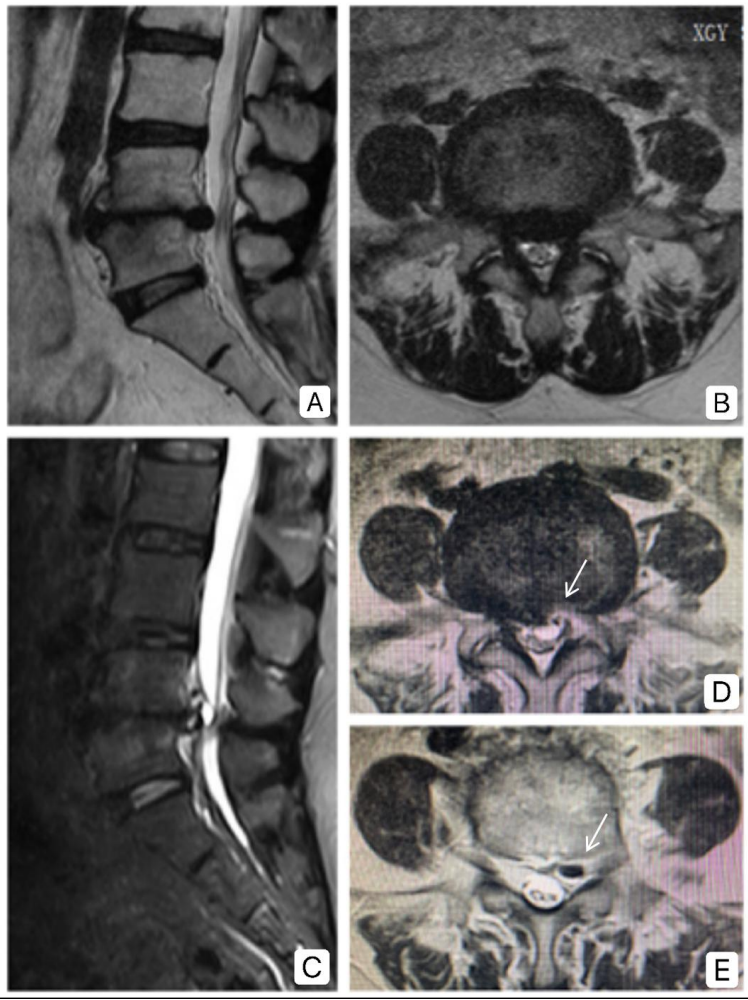

Fig. 2-1. Case 5 was a female aged 60 years old. Symptomatic pseudocyst of intervertebral disc after PELD. A-B: preoperative lumbar MRI showed L4/5 disc herniation, lateral recess stenosis and compression of the anterior edge of the dural sac.

C-E: 30 days after operation, MRI showed cystic space in L4/5 segments, which was located in the spinal canal and involved in the left intervertebral foramen area. The cyst was locally connected with the intervertebral disc $($ white $\rightarrow$ ).
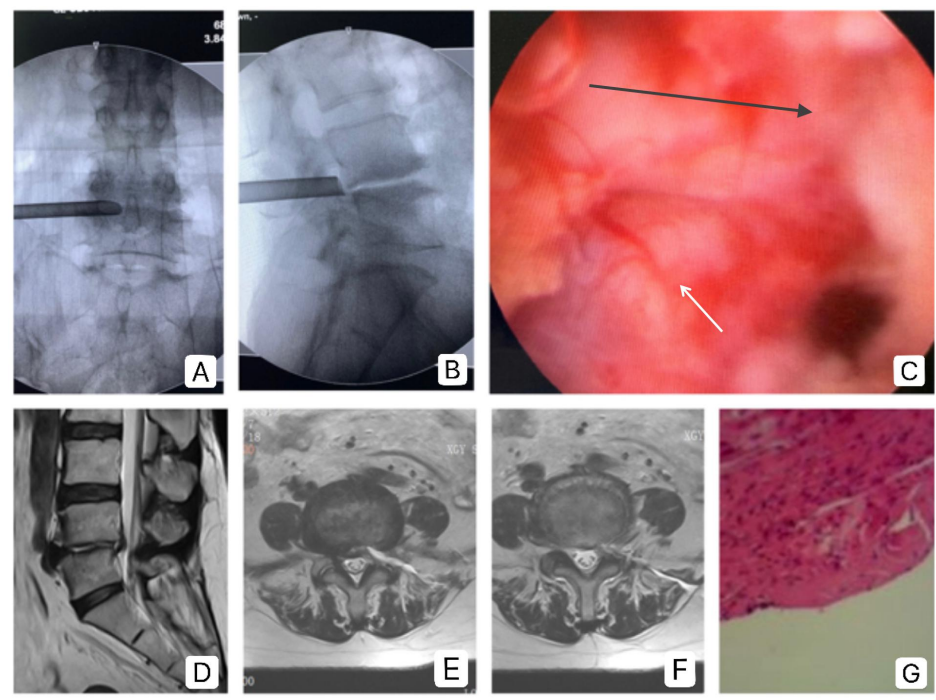

Fig. 2-2. Case 5 was a female aged 60 years old. The results of twice operations and postoperative imaging data were as follows.

A-B: percutaneous spinal endoscopic revision surgery was conducted, and C-arm fluoroscopy showed that the position of the sleeve was good.

C: Endoscopic exploration of cystic mass, dark red, compress L5 nerve root. " $\rightarrow$ " shows L5 nerve root. The "white $\rightarrow$ " indicates cystic space occupation.

D-F: Five days after revision, lumbar MRI showed that the original cyst had been removed, and there was no obvious compression on the nerve root and dural sac.

G: Postoperative pathology showed fibrous capsule tissue $(\mathrm{HE}, \times 100)$. 

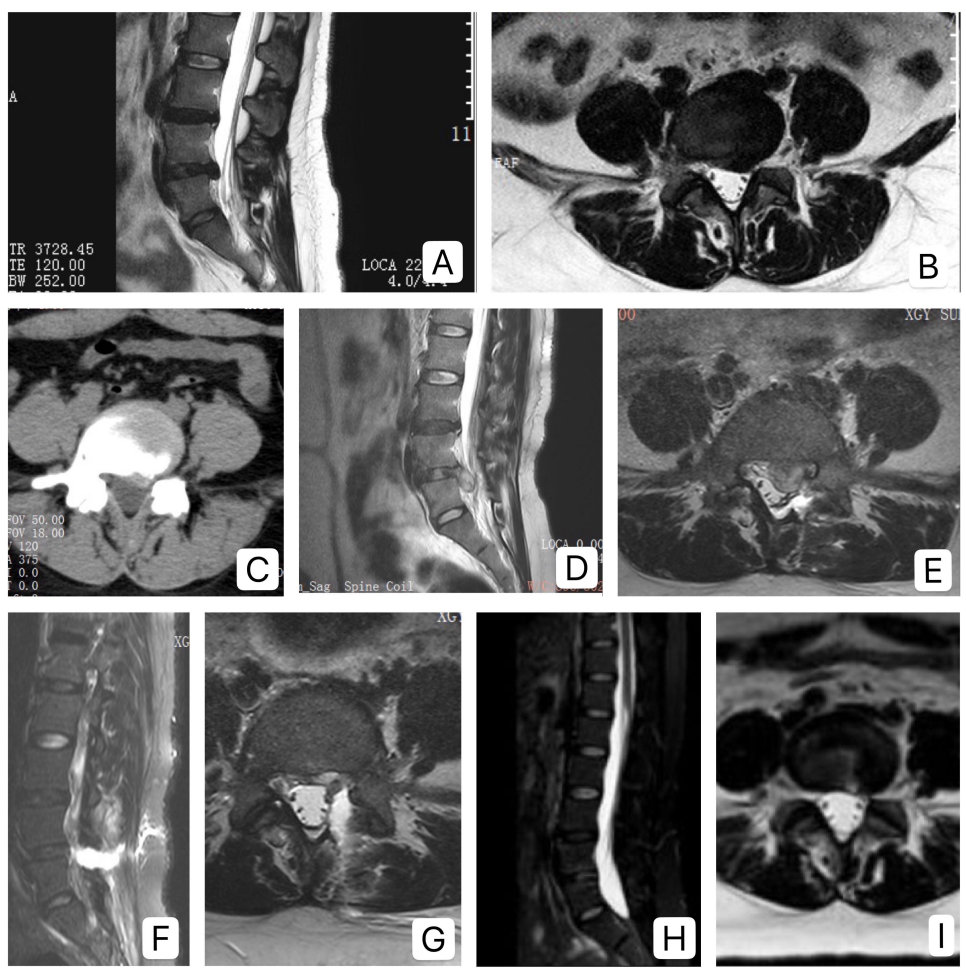

Fig. 3. Case 11 was a female aged 30yrs. Complaint: complicated with hematoma after PELD. Before operation, MRI showed lumbar L 4/5 disc herniation (A, B) and CT showed no calcification (C). Posterior PELD operation was performed smoothly. The strength of extensor digitorum dorsi decreased on the second day after operation. MRI of lumbar vertebrae showed effusion in the operation area and hematoma was considered (D, E). Emergency exploration of the original approach hole showed that the blood clot was about $1 \times 1 \mathrm{~cm}$ during the operation, which compressed the nerve root. Short-term postoperative MRI examination of lumbar vertebrae showed that the hematoma was cleared, the nerve root was not compressed, and a small amount of fluid $(F, G)$ was collected in the operation area. The last followup for one and a half years showed that the lumbar MRI was cured $(\mathrm{H}, \mathrm{I})$. 

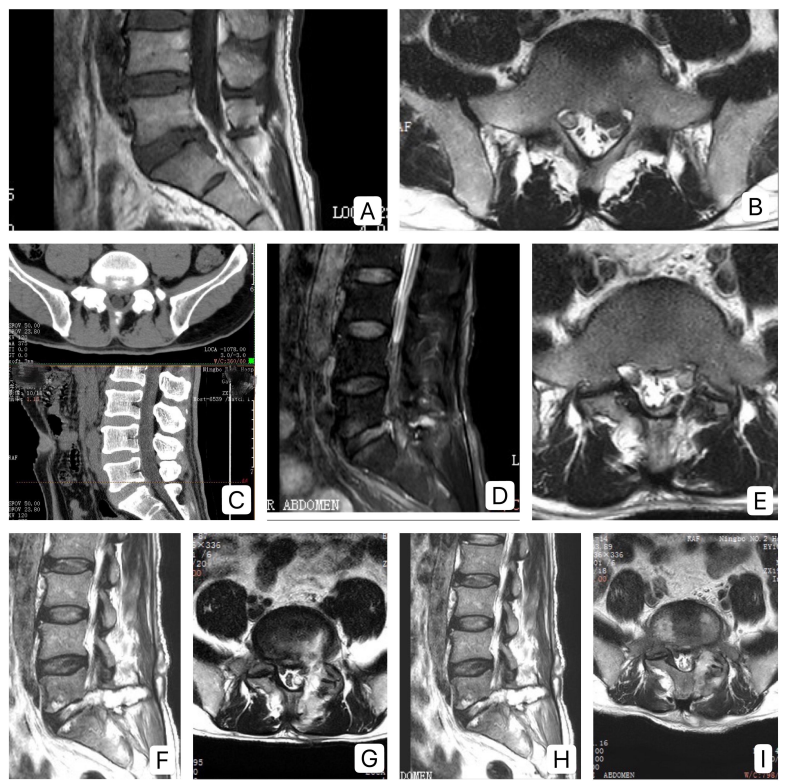

Fig. 4-1. Case 12 was a male aged 49yrs. Complaint: Infection occurred after PELD. L5/S1 intervertebral disc herniation (A/B), partial prolapse, no calcification (C). Posterior PELD was performed under general anesthesia, and the prolapsed nucleus pulposus was removed after operation. Local redness, swelling and exudation occurred after discharge ( 2 weeks after operation). MRI showed local effusion in the operative area, involving intervertebral space (F, G). Secretion culture (-) with empirical anti-infection. One month after operation, MRI did not improve (H, I).
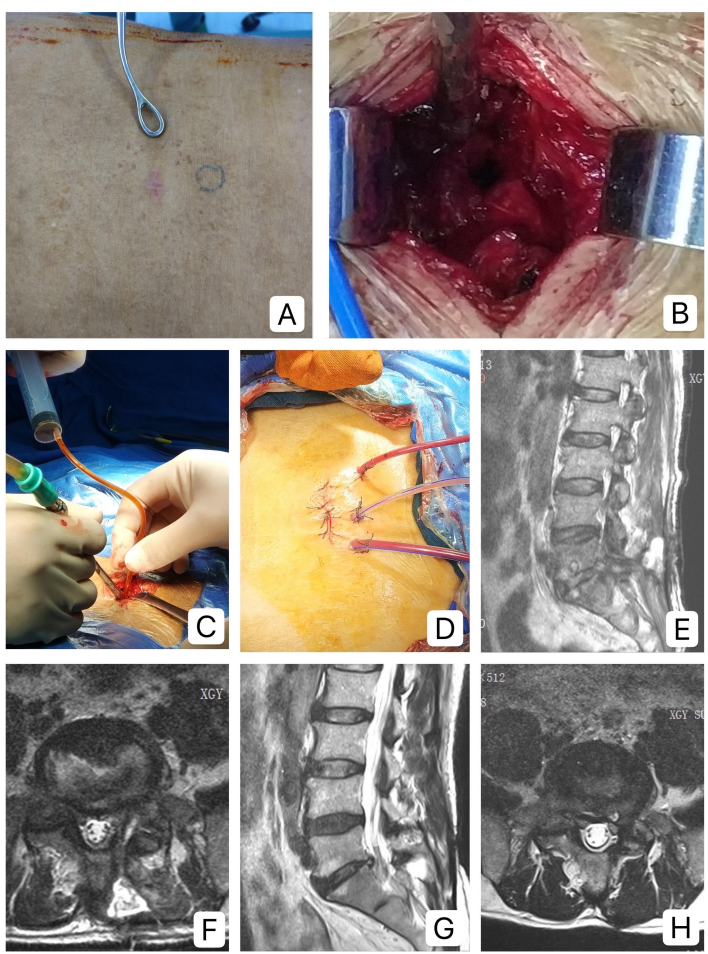

Fig. 4-2. Case 12 was a male aged 49yrs. Complaint: One month after the first operation, the original incision was slightly red and swollen (A). MED exploration was performed to determine the depth and extent of the focus, and then a small incision was changed to open debridement. During the operation, the infected focus was found to be deep into the intervertebral space (C), conducting debridement and irrigation, and drainage were placed in once and out twice (D). Bacterial culture (-). Re-examination of MRI after extubation after operation showed that the control of inflammation was improved (E, F). Two and a half years after operation, MRI showed that the condition was cured $(\mathrm{G}, \mathrm{H})$. 


\section{Reference:}

1. Kapetanakis S, Gkantsinikoudis N, Charitoudis G. The Role of Full-Endoscopic Lumbar Discectomy in Surgical Treatment of Recurrent Lumbar Disc Herniation: A Health-Related Quality of Life Approach. Neurospine. 2019 Mar;16(1):96-104.

2.Kim JM, Lee SH, Ahn Y,et al. Recurrence after successful percutaneous endoscopic lumbar discectomy[J]. Minimally Invasive Neurosurgery, 2007, 50(2): 82-85.

3.Shimia M, Babaei-Ghazani A, Sadat BE, et al. Risk factors of recurrent lumbar disk herniation[J]. Asian J Neurosurg, 2013, 8(2): 93-96.

4. Burton CV. Causes of failure of surgery on the lumbar spine: ten-year follow-up. Mt Sinai J Med. 1991 Mar;58(2):183-7.

5.Shi R, Wang F, Hong X, et al. Comparison of percutaneous endoscopic lumbar discectomy versus microendoscopic discectomy for the treatment of lumbar disc herniation: a meta-analysis. Int Orthop, 2019, 43(4): 923-937

6.Kim HS, You JD, Ju CI. Predictive Scoring and Risk Factors of Early Recurrence after Percutaneous Endoscopic Lumbar Discectomy. Biomed Res Int. 2019 Nov 7;2019:6492675.

7.Choi G, Modi HN, Prada N, et al. Clinical results of XMR-assisted percutaneous transforaminal endoscopic lumbar discectomy[J]. J Orthop Surg Res, 2013, 8(1): 14.

8.Torkian P, Daneshvar K, Taherian E, et al. Fibrin sealants in lumbar annuloplasty after endoscopic discectomy as a method to prevent recurrent lumbar disc herniation. Eur J Transl Myol. 2020;30(2):8748.

9.Suk KS, Lee HM,Moon SH,et al.Recurrent lumbar disc heniation: results of operative management[J].Spine,2001,26( 6) : 672.

10.Hao L, Li S, Liu J, et al. Recurrent disc herniation following percutaneous endoscopic lumbar discectomy preferentially occurs when Modic changes are present. J Orthop Surg Res. 2020;15(1):176.

11.Carragee EJ, Han MY, Suen PW, et al. Clinical outcomes after lumbar discectomy for sciatica: the effects of fragment type and anular competence. J Bone Joint Surg Am. 2003 Jan;85(1):102-8.

12.Choi KC, Kim JS, Lee DC, et al. Percutaneous endoscopic lumbar discectomy: minimally invasive technique for multiple episodes of lumbar disc herniation. BMC Musculoskelet Disord. 2017;18(1):329.

13.Song Z, Ran M, Luo J, et al. Follow-up results of microendoscopic discectomy compared to day surgery using percutaneous endoscopic lumbar discectomy for the treatment of lumbar disc herniation. BMC Musculoskelet Disord. 2021;22(1):160.

14.Cammisa FP Jr,Eismon FJ,Green BA. Dural Laceration occurring with burst fractures and associated laminar fractures[J]. J Bone Joint Surg Am,1989,71(7):1044-1052.

15.Keene TL,Anthony J,Benson DR.Dural tears associated with lumbar burst fractures[J].J Orthop Trauma, 1990,4(3):243-245. 
16.Carl AL,Matsumoto M,Whalen JT.Anterior dural laceration caused by thoracolumbar burst fractures[J].J Spinal Diosord,2000,13(5):399-403.

17.Gadjradj PS, Harhangi BS, Amelink J, et al. Percutaneous Transforaminal Endoscopic Discectomy Versus Open Microdiscectomy for Lumbar Disc Herniation: A Systematic Review and Metaanalysis. Spine (Phila Pa 1976). 2021;46(8):538-549.

18.Fujita N, Michikawa T, Yagi M, et al. Impact of lumbar hypolordosis on the incidence of symptomatic postoperative spinal epidural hematoma after decompression surgery for lumbar spinal canal stenosis. Eur Spine J. 2019 Jan;28(1):87-93.

19.Schroeder GD, Kurd MF, Kepler CK, et al. Postoperative Epidural Hematomas in the Lumbar Spine. J Spinal Disord Tech. 2015 Nov;28(9):313-8.

20.Young PM,Fenton DS,Czervionke LF. Postoperative annular pseudocyst:report of two cases with an unusual complication after microdiscectomy and successful treatment by percutaneous aspiration and steroid injection[J]. Spine J,2009,9(2): e9-e15.

21.Kang SH, Park SW. Symptomatic post-discectomy pseudocyst after endoscopic lumbar discectomy[J]. J Korean Neurosurg Soc, 2011, 49(1):31-36.

22. Shiboi R, Oshima Y, Kaneko T, et al. Different operative findings of cases predicted to be symptomatic discal pseudocysts after percutaneous endoscopic lumbar discectomy. J Spine Surg. 2017;3(2):233-237.

23.Jha SC, Tonogai I, Higashino K, et al. Postoperative discal cyst: An unusual complication after microendoscopic discectomy in teenagers[J]. Asian J Endosc Surg, 2016, 9(1): 89-92. 